\title{
Does Size Matter in Determining Growth of Micro, Small and Medium Enterprises (MSMEs) in Zimbabwe
}

\author{
Moses Chundu, Caren Pindiriri, Nyasha Kaseke \\ Faculty of Business Management Sciences and Economics, University of Zimbabwe, Harare, Zimbabwe \\ Email: mtgjcc@gmail.com
}

How to cite this paper: Chundu, M., Pindiriri, C., \& Kaseke, N. (2020). Does Size Matter in Determining Growth of Micro, Small and Medium Enterprises (MSMEs) in Zimbabwe. Open Journal of Business and Management, 8, 1888-1907. https://doi.org/10.4236/ojbm.2020.84115

Received: June 28, 2020

Accepted: July 27, 2020

Published: July 30, 2020

Copyright () 2020 by author(s) and Scientific Research Publishing Inc. This work is licensed under the Creative Commons Attribution International License (CC BY 4.0).

http://creativecommons.org/licenses/by/4.0/

\begin{abstract}
Micro, Small and Medium Enterprises (MSMEs) are increasingly becoming the dominant players in the economies of most countries especially in Sub Saharan Africa, constituting $97 \%$ to $99 \%$ of industry. What is worrisome though, is the high rate of failure and absence of growth in this sector despite various interventions to promote their growth which is inhibiting the contribution to economic development. This study sought to determine whether the size of enterprise affects the impact of various determinants of MSMEs growth in Zimbabwe. It used 2012 Finscope national MSMEs survey data which was modeled using probit model on a sample of 3222 MSMEs with growth as the binary dependent variable. The sector was divided into three main categories being individual, micro and the small to medium categories. The growth determinants that proved robust include, age of the firm, motivation, and education background of entrepreneur and sector whose coefficients were found to be significant in at least two of the three subcategories in addition to being significant in the main overall model. The legal form, tax status, banking status, exports and prior sector experience variables produced mixed results with coefficients being significant in at least one of the three subcategories to reflect peculiarities in the respective categories which had been lost in the aggregated model. Thus, for MSMEs growth policies to be effective, there is need to incorporate these peculiarities with respect to various size categories.
\end{abstract}

\section{Keywords}

MSMEs, Firm Size, Growth Determinants, Zimbabwe

\section{Introduction and Background}

The growing significance of Micro, Small and Medium Enterprises (MSMEs) in 
world economies ${ }^{1}$ demands that the sector be given more attention in the world of research. In the Organisation for Economic Co-operation and Development (OECD) area, MSMEs constitute approximately $99 \%$ of all firms, accounting for about $70 \%$ of employment and $50 \%-60 \%$ of value addition (OECD, 2017). Estimates of their contribution to GDP range from $12 \%$ to $60 \%$ and even higher when informal small businesses' contribution is considered (IFC, 2010).

In the context of United Nations' (UN) Sustainable Development Goals (SDGs) agenda and Africa Union's (AU) Agenda632 ${ }^{2}$ MSMEs have a greater role in promoting inclusive and sustainable economic growth, providing employment and decent work for all, promoting sustainable industrialisation and fostering innovation, and reducing income inequalities (OECD, 2017). In developing economies, it has become increasingly imperative that MSMEs are growing sustainably in order to accommodate new players from the previously marginalised groups which include women. The architecture of MSMEs sector in developing countries is such that women are the dominant players; hence promoting growth of MSMEs becomes a means to achieve equity and gender-related goals.

It is disturbing to note that despite governments' efforts to promote their growth and contribution to development, MSMEs' response especially in developing countries has not been very encouraging (OECD, 2017). This challenge is more prevalent in Zimbabwe where, despite the many quasi-fiscal support programs for the sector, MSMEs growth remains a challenge (Sachikonye \& Sibanda, 2016). The Finscope MSME Survey Zimbabwe 2012, blames the lack of accurate and dependable information about the sector being the main obstruction to the crafting of evidence-based interventions to promote the sector sustainably (Strassburg \& Khumalo, 2012). Empirical evidences so far (Karedza, Nyamazana, Mpofu, \& Makurumidze, 2014; Chipangura \& Kaseke, 2012; Mudavanhu, Bindu, Chigusiwa, \& Muchabaiwa, 2011; Zindiye, 2008) all seem to suggest the absence of growth ${ }^{3}$ even in the face of some deliberate efforts to support the sector, hence the need to understand better what determines small firm growth in the various size categories in Zimbabwe.

The rest of the paper is organised as follows. Section 2 gives a brief profile of the MSMEs sector in Zimbabwe followed by the review of literature in Section 3. Section 4 gives the methodology, followed by presentation and discussion of econometric results. The paper concludes by giving a summary and policy implications of the study.

\section{Profile of MSMEs Sector in Zimbabwe}

The Finscope MSME Survey Zimbabwe 2012 data when disaggregated by ${ }^{1}$ Most countries have between $97 \%$ and $99 \%$ of businesses being in the SMEs category with the exception of a few outliers mainly due to data accuracy issues (OECD, 2017).

${ }^{2}$ With less than eleven years remaining to the 2030 target for SDGs, issues of poverty reduction, inclusiveness (gender equity-goal no. 5 and reducing inequality-goal no. 10) and greening the economy (sustainable production goal no. 12) needs to be accelerated.

${ }^{3}$ The Finscope data shows a relatively young MSMEs sector with $71 \%$ of the businesses having been in operation for 5 years or less and a mere $8 \%$ surviving to maturity with the majority of them remaining micro in size suggesting little or no growth over time (Strassburg \& Khumalo, 2012). 
MSMEs sub-category reflected the following sector characteristics as presented in Table 1. The sector is highly skewed in favour of individual entrepreneurs/sole proprietors constituting $71 \%$, followed by micro enterprise at $24 \%$ and lastly small to medium enterprises at $5 \%$.

The sole proprietors' category which dominated the sample is characterised by low entry barriers in terms of start-up capital as well as other regulatory and operational constraints. With zero employees, there are no human resource challenges though the absence of employees tends to negatively affect the minimum skills endowment necessary to guarantee success in business. The data ${ }^{4}$ shows that the age of sole proprietors ranged from as low as 18 years to 82 years with a mean age of 39 years suggesting that age is not a barrier to participate in this sub-category. The age of the firms in this category ranged from 0 - 62 years with a mean of 6.3 years suggesting that the majority of them were still in the start-up to early establishment phases.

The micro sector is defined, in terms of the Small Enterprises Development Corporation Amendment of 2011 definition of MSMEs, as a business employing between 1 and 5 employees which is the proxy for size in this study. The mean size of 2.2 employees suggests that the majority of the micro enterprises are straying on the lower end of the range. This could also be an indication of the age of the businesses whose ages range from 0 years to 57 years with a mean of 7.7 years like the sole proprietorship, qualifying in the start-up to early establishment phases. The age of the business owners ranged from 19 years to 81 years with a mean age of 41 years, also quite similar to the trend with sole proprietors.

The small to medium enterprises (SMEs) category had the smallest representation in the sample at 5\% with firm size ranging from 6 employees to $64 \mathrm{em}$ ployees averaging 12.4 employees per firm. The average fell more in the small part of the combined category with a ceiling of 35 employees, thus very few businesses qualified to be in the medium enterprises category which should be employing between 36 and 75 employees in terms of the new definition. Age of the firm ranged from 0 years to 42 years with a mean of 10.2 suggesting that there were still a few in the start-up phase who were starting big hence a minimum of 0 years. The age of the entrepreneur was between 20 years and 78 years averaging 44 years, a pattern not significantly different from the individual and micro categories.

Table 1. Composition of MSMEs in Zimbabwe.

\begin{tabular}{cccc}
\hline & Number of employees & Sample Size & $\begin{array}{c}\text { Percentage of } \\
\text { business owners }\end{array}$ \\
\hline Individual entrepreneurs & 0 & 2314 & $71 \%$ \\
Micro businesses & $1-5$ & 762 & $24 \%$ \\
Small and Medium businesses & $6-75$ & 142 & $5 \%$ \\
\hline
\end{tabular}

Source: Finscope Survey 2012

${ }^{4}$ These descriptive statistics in this section were computed from the Finscope 2012 Survey data. 


\section{Literature Review}

Gibrat's (1931) theory of the firm is the foundational theory though not supported much by empirical findings (McMahon, 1998). Later conceptions in the form of the Churchill and Lewis (1983) Stages Growth Model and the deterministic approaches which incorporate resource based view and dynamic capability view have become useful guides in the conceptual framework for the study of small firm growth. The Lewis-Churchill model views growth of the firm occurring similar to the way humans develop in linear stages where one stage is both a cause and effect of the other. Variations in growth reflect the way a firm responds to different stimuli or challenges at each stage of growth. This response in turn, is a function of five management factors namely; managerial style, organisational structure, extent of formal systems, major strategic goals and the owner's involvement in the business. Critics of this model challenge the postulation of "a growth process through a sequence of stages or crises without offering any supporting evidence" (Dobbs \& Hamilton, 2007: p. 299).

Under the deterministic approach, emphasis is on core competencies as the key drivers of growth where firms grow because of the ability of managers to sense, grab and exploit new growth opportunities and not so much of the physical resources they possess. The ability to seize these opportunities reflect strong dynamic capabilities which include critical levels of entrepreneurial orientation and the ability to recognise, assimilate and apply external knowledge as part of a vibrant, iterative process (Shin \& Park, 2013). This view is contrary to Penrose (1959) earlier assertions that growth can be explained by slack resources in the firm which could have been acquired in higher quantities than actually needed in the early phases of growth. This theory had been criticised on the basis that young firms in start-up phase usually suffer resources constraints to the contrary and therefore cannot have them available in excess, thus failing to account for small firm growth especially in developing countries. Given the multiplicity of growth theories emphasising different possible causes of small firm growth, a multidisciplinary approach has been suggested combining stochastic and deterministic approaches in explaining firm growth (Federico et al., 2012). In this case, firm growth is viewed as a function of management quality, customer tastes and government policy among others; each variable accounting for only a very small portion of the proportionate growth/decline of businesses, but together acting randomly on the sizes of firms (Dobbs \& Hamilton, 2007: p. 298).

The concept of growth is studied from a wide array of standpoints ${ }^{5}$ across different geographical locations and across different sectors (Wiklund, 1998). The challenge of heterogeneity thus, implies difficulty of comparing empirical findings (Storey, 1994). Firm growth studies in Zimbabwe (Karedza et al., 2014; Chipangura \& Kaseke, 2012; Mudavanhu et al., 2011; Zindiye, 2008), are modelled around what are known as "barriers" studies with their inherent weakness${ }^{5}$ The methodological variations relate to choice of proxy for growth variable, sample size, and choice of reference time periods (Storey, 1994; Woldie, Leighton, \& Adesua, 2008). 
es. Such studies capture possible constraints to firm growth from the perspective of the owner/manager and tend to miss on key non-environmental constraints to MSMEs growth. Thus, the responses end up reflecting what is called "barrier rhetoric" as opposed to personal experience, mostly influenced by a desire to justify financial support especially in developing countries (Doern, 2009).

The results from literature are mixed, reflecting wide variations in study approaches (Wiklund, 1998). Delmar \& Davidsson (1998) posit that the mixed results are partly due to measurement problems as far as the growth concept is concerned; more so given that most researchers use cross-sectional data relying on somewhat small samples, hence data constraints that tends to limit the understanding of firm growth dynamics. There is, however, general agreement on the significance of the following MSMEs growth determinants; age of owner, education, prior management experience of the owner, motivation for being in business, firm size, legal status of the firm, location, regulation level and taxation policy.

Storey (1994), reviewed 17 studies and found no relationship between educational backgrounds and growth in nine studies, but there was some form of positive relationship in eight studies. The differential results being attributed to cross country variability in the measurement of the education variable (Tuan \& Yoshi, 2009). Studies carried out in Africa being Nigeria (Mambula, 2002; Okpara, 2011), Ghana (Yeboah, 2015), South Africa (Fatoki, 2011) and Zimbabwe (Mudavanhu et al., 2011), equally found education of the business owners/managers to be a significant positive growth determinant. However this education is more useful when acquired before getting into enterprises than when acquired whilst in business (Federico, Rabetino, \& Kantis, 2012). Findings on the influence of prior sector experience on MSMEs growth in developed countries are mixed with five studies from Storey (1994) showing no relationship at all whilst three showed prior sector experience being associated with slower-growing firms. Other studies to confirm this include Nichter and Goldmark, (2009); Federico, Rabetino and Kantis (2012) and Mbugua et al. (2013).

Storey's (1994) findings on motivation for starting a business show that previously unemployed founders are unlikely to grow their businesses as rapidly as where the founder was previously employed, hence leveraging the skills acquired in formal employment. This was also confirmed by other studies (Sirec \& Mocnik, 2010; Strassburg \& Khumalo, 2012) ${ }^{6}$. Empirical evidence on the effect of the age of the entrepreneur has shown that young entrepreneurs are most likely to start firms that grow largely because they have the energy, the necessary commitment and the motivation to do so compared to their older counterparts (Blackburn, Hart, \& Wainwright, 2013; Kangasharju, 1999; Storey, 1994; Woldie, Leighton, \& Adesua, 2008). Social networks can also play an important role in ${ }^{6}$ According to the Finscope Survey 2012; 63\% of MSMEs owners cite unemployment/poverty/survival as the motivation to be in business. It is not surprising then that $23 \%$ of the entrepreneurs said they would close their business if they were offered a job somewhere (Strassburg \& Khumalo, 2012). 
helping entrepreneurs deal with environmental challenges through creation of critical conduits that result in new prospects for innovation, technological advancement and long-term enterprise sustainability (Rogerson, 2001: p. 137). Other studies supporting this view include Havnes and Senneseth (2001) and Florin, Lubatkin and Schulze (2003).

Young firms tend to grow more rapidly than old ones (Almus \& Nerlinger, 2000; Sleuwaegen \& Goedhuys, 2002; Storey, 1994; Wijewardena \& Tibbits, 1999). Small firms also tend to grow faster than large firms (Becchetti \& Trovato, 2002; Delmar \& Davidsson, 1998; Garnsey, Stam, \& Hefferman, 2006; Hamilton \& Lawrence, 2001; Reichstein \& Dahl, 2004; Yasuda, 2005). The reason being that small firms is able to evade government regulations and taxation, something large firms cannot do (Snodgrass \& Biggs, 1996). However, Audretsch and Klepper (2000) found to the contrary that large technology firms in England had higher growth prospects than smaller firms since the later suffer productivity losses as they become older due to declining investments (Woldie, Leighton, \& Adesua, 2008).

Legal Status of an enterprise affects growth prospects through influencing access to capital according to studies by Olson and Bokor (1995); Orser, Hogarth-scott and Riding (2000); and Davidsson et al. (2002). There are, however, some isolated studies that found significant growth among sole proprietorship firms (Storey, 1994; Woldie, Leighton, \& Adesua, 2008). In the case of Zimbabwe it is not so much a choice of legal status but a choice of being registered or not being registered at all with a mere $15 \%$ registered, but not necessarily incorporated (Strassburg \& Khumalo, 2012). Whilst the operating environment has significant impact on business innovation and growth in general, it is acknowledged that young and old firms are the most affected (OECD, 2017).

\section{Methodology}

Finscope 2012 survey data was used covering 3222 small business owners/managers across Zimbabwe. The survey followed a multi-stage sampling process which ensured a fair national representation of the respondents. The choice of survey data being informed by the fact that it is the best source where there is need to capture information on attitudes, perceptions, strategies, and resources from a large number of cases (Sirec \& Mocnik, 2010). The model was guided by the one by Federico et al. (2012: p. 576) who proposed that "young firm growth could be explained by a combination of several perspectives, namely the entrepreneurs' profile, the firm's resources and the market's characteristics". This model recognises the complexity of the growth concept which has meant different methodologies for different studies, making comparability a challenge (Davidsson et al., 2005; Sirec \& Mocnik, 2010). The model recognises that any experiential study examining determinants of firm growth is to some extent reductionist in that it can examine only a fraction of the factors important for firm growth (Gielnik, Zacher, \& Schmitt, 2017). 
Orser et al. (2000) used similar approach to the one by Delmar \& Davidsson (1998), in which they modelled the SMEs into four size categories namely micro, mini, small and medium similar to the current categorisation in Zimbabwean SMEs sector which breaks the micro category into sole proprietors (0 employees) those employing 1 - 5 employees as micro and those employing 6 - 75 employees as small to medium. Guided by theoretical and empirical review the model is specified as follows:

$$
\begin{aligned}
\text { GROWTH }_{i}= & a_{0}+\beta_{1} \mathrm{LF}_{i}+\beta_{2} \mathrm{PSE}_{i}+\beta_{3} \mathrm{ED}_{i}+\beta_{4} \mathrm{MOT}_{i}+\beta_{5} \mathrm{AGE}_{i} \\
& +\beta_{6} \mathrm{AGEF}_{i}+\beta_{7} \mathrm{EXP}_{i}+\beta_{8} \mathrm{BANK}_{i}+\beta_{9} \mathrm{GEN}_{i}+\beta_{10} \mathrm{MS}_{i} \\
& +\beta_{11} \mathrm{TEC}_{i}+\beta_{12} \mathrm{TAXP}_{i}+\beta_{13} \mathrm{SECj}_{i}+\varepsilon_{i}
\end{aligned}
$$

Equation (1) above tests the significance of all the variables combined on growth where $\mathrm{GROWTH}_{i}=$ growth of firm $i$ across all industries and the other variables as defined in Table 2. $\varepsilon_{i}=$ the error term or a random disturbance that is uncorrelated with the regressors and $\beta_{i}=$ the slope at mean showing the marginal effects of the variables on the dependent variable.

Since the study covered the whole country, it is possible that it can be a source of distortion in sampling given the heterogeneous nature of the sector. To deal with this potential challenge, the data was further divided into different size categories. The composition of MSMEs in Zimbabwe is skewed in favour of individual entrepreneurs/sole proprietors constituting $71 \%$ of the MSMEs. It is, therefore, possible that the dominance of this category of MSMEs has potential to drown other categories so as to compromise the precision of resultant policy prescriptions. To mitigate the effects of this phenomenon, Equations (2)-(4) below were estimated on the same variables across the different categories ${ }^{7}$.

$$
\begin{aligned}
\text { GROWTH }_{i \mathrm{IE}}= & a_{0}+\beta_{1} \mathrm{LF}_{i}+\beta_{2} \mathrm{PSE}_{i}+\beta_{3} \mathrm{ED}_{i}+\beta_{4} \mathrm{MOT}_{i}+\beta_{5} \mathrm{AGE}_{i} \\
& +\beta_{6} \mathrm{AGEF}_{i}+\beta_{7} \mathrm{EXP}_{i}+\beta_{8} \mathrm{BANK}_{i}+\beta_{9} \mathrm{GEN}_{i}+\beta_{10} \mathrm{MS}_{i} \\
& +\beta_{11} \mathrm{TEC}_{i}+\beta_{12} \mathrm{TAXP}_{i}+\beta_{13} \mathrm{SECj}_{i}+\varepsilon_{i} \\
\mathrm{GROWTH}_{i \mathrm{MB}}= & a_{0}+\beta_{1} \mathrm{LF}_{i}+\beta_{2} \mathrm{PSE}_{i}+\beta_{3} \mathrm{ED}_{i}+\beta_{4} \mathrm{MOT}_{i}+\beta_{5} \mathrm{AGE}_{i} \\
& +\beta_{6} \mathrm{AGEF}_{i}+\beta_{7} \mathrm{EXP}_{i}+\beta_{8} \mathrm{BANK}_{i}+\beta_{9} \mathrm{GEN}_{i}+\beta_{10} \mathrm{MS}_{i} \\
& +\beta_{11} \mathrm{TEC}_{i}+\beta_{12} \mathrm{TAXP}_{i}+\beta_{13} \mathrm{SECj}_{i}+\varepsilon_{i} \\
= & a_{0}+\beta_{1} \mathrm{LF}_{i}+\beta_{2} \mathrm{PSE}_{i}+\beta_{3} \mathrm{ED}_{i}+\beta_{4} \mathrm{MOT}_{i}+\beta_{5} \mathrm{AGE}_{i} \\
& +\beta_{6} \mathrm{AGEF}_{i}+\beta_{7} \mathrm{EXP}_{i}+\beta_{8} \mathrm{BANK}_{i}+\beta_{9} \mathrm{GEN}_{i}+\beta_{10} \mathrm{MS}_{i} \\
& +\beta_{11} \mathrm{TEC}_{i}+\beta_{12} \mathrm{TAXP}_{i}+\beta_{13} \mathrm{SECj}_{i}+\varepsilon_{i}
\end{aligned}
$$

See Table 2 for the definition of variables used in the above models and their expected signs from literature.

Growth (GROWTH) is measured by a dummy variable from a qualitative question measuring how well a firm did in the year of reference compared to the previous year. It is a binary dependent variable measuring growth as perceived by the owner. The respondents were left to define growth whichever way they related with best, as long as they considered their businesses to have grown during ${ }^{7}$ The three categories are; Individual entrepreneurs (IE), Micro businesses (MB) and Small and Medium businesses (SMB). 
Table 2. Summary of explanatory variables \& expected signs.

\begin{tabular}{ccc}
\hline Variable Name & Variable Description & Expected Sign \\
\hline GROWTH & Dummy measuring whether a firm grew or not & \\
SECj & Sector dummy for sector $j$ & $+/$ \\
AGEF & Age of firm in years from the date firm was birthed. & + \\
LF & Legal form/status of the business. & + \\
MOT & Motivation of entrepreneur for getting into business & + \\
PSE & Prior sector experience of the entrepreneur & + \\
AGE & Age of business owner in years. & + \\
EXP & Exports as a proxy for competitiveness. \\
ED & Educational background of the entrepreneur measured by & + \\
TAXP & number of years of schooling. & + \\
BANK & Bax payment measuring status of the firm. & + \\
GEN & Gender of the entrepreneur. & + \\
MS & Marital status of the entrepreneur. & + \\
TEC & Technology use & + \\
\hline
\end{tabular}

the reference period. Okpara (2011) also used a similar approach in a study of growth determinants in Nigeria, citing the difficulty of obtaining accurate quantitative data in Africa.

Qualitative response (QR) models were employed. QR models apply in case of limited dependent variable (LDV) model where the dependent variable is an indicator of a discrete choice, such as a "yes or no" decision. In general, conventional regression methods are inappropriate in these cases (Greene, 2002). The method of estimation in this case is the maximum likelihood using the probit binary estimation procedure. Goodness of fit test employed the likelihood ratio test that all the slope coefficients in the probit model are zero (Greene, 2002: p. 679). Gretl software was used for estimation which has a way of dealing with the perfect prediction problem common in LDV models. In this case, the offending variable is automatically dropped from the model and estimation proceeds with the reduced specification. Gretl also performs a conditional moment test on skewness and kurtosis which is printed automatically as a test for normality (Cottrell \& Lucchetti, 2016). Omitted variables test was also carried out using sequential elimination method. However, the substantive results of probit analysis are quite robust and do not suffer much from the effects of omitted variables (Cramer, 2005).

\section{Presentation and Discussion of Results}

\subsection{Descriptive Statistics}

Table 3 gives the frequency distribution of the responses to the key variables 
Table 3. Frequency of responses for variables in the sole proprietor category.

\begin{tabular}{ccccccccccc}
\hline & \multicolumn{2}{c}{ MOT } & \multicolumn{2}{c}{ LF } & \multicolumn{2}{c}{ PSE } & \multicolumn{2}{c}{ TAXP } & \multicolumn{2}{c}{ BANK } \\
\hline & Count & $\%$ & Count & $\%$ & Count & $\%$ & Count & $\%$ & Count & $\%$ \\
\hline NO (0) & 1292 & 56 & 2065 & 89 & 2147 & 93 & 2302 & 99 & 2036 & 88 \\
YES (1) & 1022 & 44 & 242 & 10 & 167 & 7 & 12 & 1 & 278 & 12 \\
\hline
\end{tabular}

in the model specific to the sole proprietor category. The majority (56\%) of the respondents revealed that they were in business out of necessity while a mere 7\% confessed to having prior sector experience before venturing into business. On firm characteristics, a whopping $89 \%$ were not formally/legally registered, whilst only $12 \%$ had business bank accounts. A paltry $1 \%$ confessed to having their tax affairs in order. Thus, it would appear the high degree of informality of the MSMEs sector was being driven largely by the dominant sole proprietors.

Regarding the education levels ${ }^{8}$ of the owner (as depicted in Figure 1), the majority had at least the basic education ${ }^{9}$ to guarantee literacy with the majority (39.5\%) having completed at least secondary education up to ordinary level. However, the education levels that matter in determining performance in business is mostly tertiary education from level $7-8$ where practical skills relevant to one's field are acquired.

For the micro category, a close look at Table 4 shows a majority (56\%) of the respondents being in business out of choice, with $12 \%$ confessing to having prior sector experience before venturing into business. The statistics shows a significant improvement in these two variables when compared with the sole proprietor category which can, in part, be explained by the aspect of survival bias in the sample as some of those with wrong motives and no prior experience would have succumbed before they get to hire anyone in their businesses. On firm characteristics, the proportion not formally/legally registered stood significantly lower at $75 \%$ whilst the proportion with business bank accounts remained at $12 \%$, the same level with sole proprietors. The percentage paying taxes is slightly higher at $3 \%$, a percentage that is still worrisome.

Regarding the education levels of the owner, the pattern is similar to that of sole proprietor except that there is now a significant percentage (16\%) in the 7 8 education level which entails possession of tertiary skills likely to be relevant in one's line of business.

Table 5 shows progressively better variable performance for the SMEs category compared to the individual and micro categories across all variables. This reflects the fact that most businesses in this category happen to be mature businesses given that the survey was not done over time to give time series data but picked a position at a given point in time.

The owner characteristics variables also improved significantly with 58\% ${ }^{8} 1$ = No schooling; 2 = Primary School; 3 = Grade $7 ; 4$ = Incomplete secondary; 5 = Complete Secondary; 6 = A level; 7 = College; $8=$ University (Graduate/Post graduate degree).

${ }^{9}$ Basic education level is defined as completion of ' $O$ ' Level equivalent to Cambridge's GCSE level. 


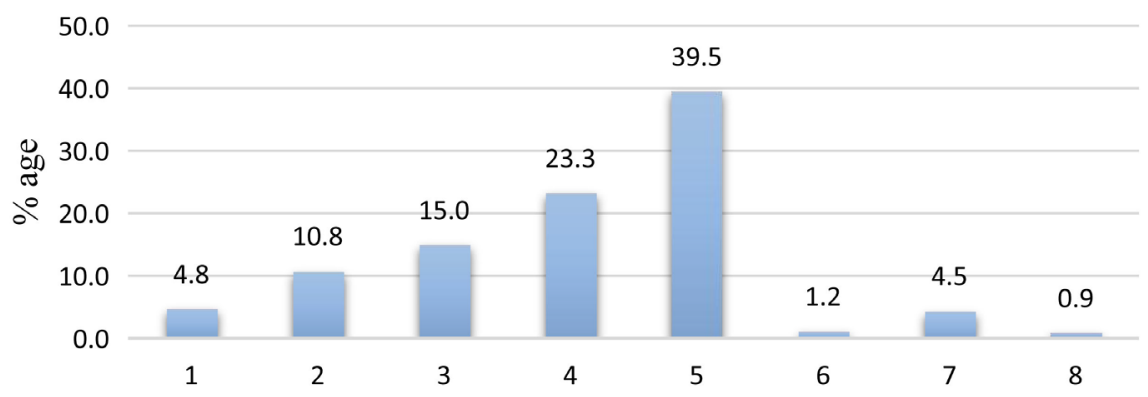

Level of Education-1 being no education \& 8 the most educated postgrad degree.

Figure 1. Owner education trends for sole proprietors.

Table 4. Frequency of responses for variables in the micro size category.

\begin{tabular}{cccccccccccc}
\hline & \multicolumn{2}{c}{ MOT } & \multicolumn{2}{c}{ LF } & \multicolumn{2}{c}{ PSE } & \multicolumn{2}{c}{ TAXP } & \multicolumn{2}{c}{ BANK } \\
\hline & Count & $\%$ & Count & $\%$ & Count & $\%$ & Count & $\%$ & Count & $\%$ \\
\hline NO (0) & 339 & 44 & 571 & 75 & 671 & 88 & 738 & 97 & 672 & 88 \\
YES (1) & 423 & 56 & 186 & 24 & 91 & 12 & 24 & 3 & 90 & 12 \\
\hline
\end{tabular}

Table 5. Frequency of responses for variables in the SMEs size category.

\begin{tabular}{cccccccccccc}
\hline & \multicolumn{2}{c}{ MOT } & \multicolumn{2}{c}{ LF } & \multicolumn{2}{c}{ PSE } & \multicolumn{2}{c}{ TAXP } & \multicolumn{2}{c}{ BANK } \\
\hline & Count & $\%$ & Count & $\%$ & Count & $\%$ & Count & $\%$ & Count & $\%$ \\
\hline NO (0) & 62 & 42 & 86 & 59 & 123 & 84 & 129 & 88 & 125 & 86 \\
YES (1) & 84 & 58 & 59 & 40 & 23 & 16 & 17 & 12 & 21 & 14 \\
\hline
\end{tabular}

indicating they had positive motivation to be in business whilst $16 \%$ confessed to having prior sector experience (significantly higher than $12 \%$ and $7 \%$ for micro and individual categories respectively). On firm characteristics, the proportion not formally/legally registered stood significantly lower at 59\% whilst the proportion with business bank accounts improved marginally to $14 \%$. The challenges around banking seem to be shared across all size categories. The percentage paying taxes was significantly higher at $12 \%$, largely because as mature businesses, surviving without being tax compliant become increasingly costly. This is due to enhanced visibility of the business and the need to access bigger tenders which require tax compliance as a prerequisite to tender.

Regarding the education levels of the owner (as depicted in Figure 2), besides the majority having basic literacy, an even higher proportion had attained tertiary education beyond high school at $23.3 \%{ }^{10}$ (compared to $16 \%$ for the micro category). This high percentage could actually explain why most of the businesses had survived to the established/maturity stages being over 7 years of age given a mean firm age of 10 years.

${ }^{10}$ Made up of $17.1 \%$ who had attained college education plus $6.2 \%$ who had attained a university degree. 


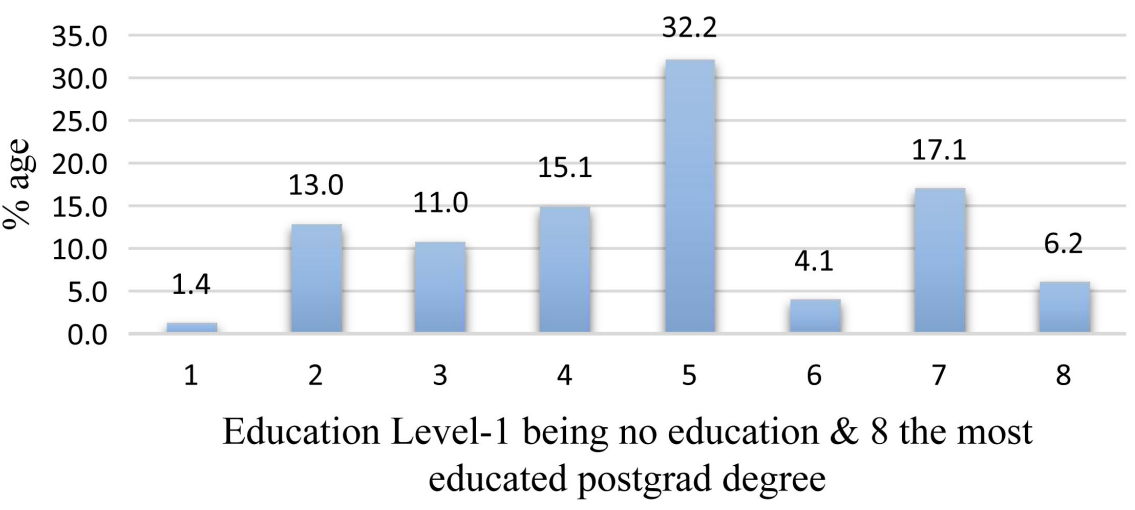

Figure 2. Owner education trends for SMEs size category.

\subsection{Probit Estimation Results}

The overall model (Equation (1)) was estimated using sub-samples by size as classified in Table 1, estimated in Equations (2)-(4) specified in the methodology. Table 6 and Table 7 present a summary of results showing $P$-values and significance levels of key variables and marginal effects and signs of effects respectively, in the process comparing results from the overall model with specific results on sub-categories. The probit models run using the Gretl software performed well in terms of their predictive power, explaining between $60 \%$ and $63 \%$ of the cases and passing the goodness of fit tests. In terms of the rest of the diagnostics, the disaggregated models passed all critical tests which include, collinearity test, $\log$ likelihood test and omitted variable tests.

There were significant variations in the behaviour of growth determinants across different size categories of the MSMEs sector. The variables that exhibited robust effects across most sub-categories consistent with the results of the macro model included age of the firm (AGEF), and motivation (MOT). On age of the firm, the results are consistent with the findings by Woldie, Leighton and Adesua (2008) who concluded that young firms tend to have better chances of growth than older firms as old firms suffer productivity losses as they become older due to failure to invest sufficiently in existing or emerging technologies.

The coefficient of the motivation (MOT) variable carried the expected positive sign in all categories and was significant except in the case of SMEs. This could be explained by the demographics of the various categories. The first two are composed of fairly young enterprises which were started during the period of high layoffs from formal employment creating a good mix of those who entered into business deliberately and those who were forced by circumstances.

A 2017 survey by Zimbabwe National Chamber of Commerce (ZNCC) confirmed this trend finding that $40.1 \%$ of respondents fell in this category with a mere $6.4 \%$ confirming to have passion for the business they were involved in (ZNCC, 2017). The results show that those who entered business consciously stand a better chance of growing their enterprises than those who "find" themselves 
Table 6. Summary of regression results by MSME category; $P$-values. (Dependent variable: GROWTH)

\begin{tabular}{ccccccccc}
\hline Sector & Overall Model & $\begin{array}{c}\text { Individual Sector } \\
(\mathbf{0} \text { employees })\end{array}$ & $\begin{array}{c}\text { Micro Sector } \\
(1-5 \text { employees })\end{array}$ & $\begin{array}{c}\text { Small to } \\
\text { Medium Sector } \\
(6-75 \text { employees })\end{array}$ \\
\hline Variable & & & & & & & & \\
LOS & $P$-value & LOS & $P$-value & LOS & $P$-value & LOS & $P$-value \\
PSE & $*$ & 0.7140 & NS & 0.7632 & NS & 0.9889 & $* *$ & 0.0025 \\
ED & $* * *$ & $<0.0001$ & $* * *$ & $<0.0001$ & NS & 0.3081 & NS & 0.3270 \\
MOT & $* * *$ & 0.0002 & $* * *$ & 0.0095 & $* *$ & 0.0248 & NS & 0.6288 \\
AGE & NS & 0.8473 & NS & 0.8187 & NS & 0.9001 & NS & 0.7260 \\
AGEF & $* * *$ & 0.0003 & $* *$ & 0.0142 & $* * *$ & 0.0028 & $*$ & 0.0501 \\
EXP & NS & 0.3899 & NS & 0.9830 & NS & 0.1490 & N/A & N/A \\
BANK & $*$ & 0.0656 & NS & 0.2972 & NS & 0.2353 & NS & 0.1575 \\
GEN & NS & 0.1357 & NS & 0.7183 & NS & 0.1932 & N/A & N/A \\
MS & NS & 0.8232 & NS & 0.9198 & NS & 0.9794 & N/A & N/A \\
TEC & NS & 0.6844 & NS & 0.6351 & NS & 0.7687 & N/A & N/A \\
TAXP & $*$ & 0.0777 & NS & 0.4124 & $*$ & 0.0989 & NS & 0.5931 \\
SECM & NS & 0.8804 & NS & 0.1437 & NS & 0.4613 & $*$ & 0.0838 \\
SECWR & $* * *$ & 0.0041 & $* * *$ & 0.0003 & NS & 0.7031 & NS & 0.9227 \\
SECA & $* * *$ & $<0.0001$ & NS & 0.3600 & NS & 0.5341 & N/A & N/A \\
\hline
\end{tabular}

${ }^{* *} p<0.01,{ }^{* *} p<0.05,{ }^{*} p<0.1$. NS $=$ Not significant; N/A = not applicable where variable was automatically excluded from the model.

in business out of necessity. The insignificant results in the case of SMEs could be explained in part by the small sample size of 142 and the fact that most of these would be the mature businesses that survived and therefore likely to be the ones that had the right motivation from the start. This is part of the survival bias that was inherent in the nature of the data which could not capture the businesses that had failed. When put together in the above context, both the significance and insignificance of the motivation factor under different categories points towards the importance of motivation in determining the growth of MSMEs.

The coefficient on education variable (ED) had the expected significant positive relationship with growth of the small firm in the case of sole proprietors and the micro-enterprises categories with a combined $95 \%$ weight on the sample. It was, however, insignificant in the case of small to medium sized enterprises (SMEs) constituting 5\% of the sample. This surprising insignificance could actually be in support of the significance of education level in determining growth potential of small firms. The reason being, by virtue of their size (ranging from 6 - 75 employees), there is a high chance the SMEs would have mitigated the obvious impact of lack of education on their part through employing educated 
Table 7. Summary of regression results by MSME size category; Marginal effects ${ }^{11}$. (Dependent variable: GROWTH)

\begin{tabular}{|c|c|c|c|c|c|c|c|c|}
\hline Sector & \multicolumn{2}{|c|}{ Overall Model } & \multicolumn{2}{|c|}{$\begin{array}{l}\text { Individual Sector } \\
\text { (0 employees) }\end{array}$} & \multicolumn{2}{|c|}{$\begin{array}{c}\text { Micro Sector } \\
\text { (1 - } 5 \text { employees) }\end{array}$} & \multicolumn{2}{|c|}{$\begin{array}{c}\text { Small to } \\
\text { Medium Sector } \\
\text { (6 - } 75 \text { employees) }\end{array}$} \\
\hline & LOS & Sign/Slope & LOS & Sign/Slope & LOS & Sign/Slope & LOS & Sign/Slope \\
\hline LF & NS & + & NS & + & NS & - & ** & +0.0116 \\
\hline PSE & * & -0.0062 & NS & - & NS & + & * & +0.2446 \\
\hline ED & $* * *$ & +0.0416 & $* * *$ & +0.0505 & NS & + & NS & + \\
\hline MOT & $* * *$ & +0.0693 & $* * *$ & +0.0529 & $* *$ & +0.0986 & NS & + \\
\hline AGE & NS & - & NS & - & NS & + & NS & + \\
\hline AGEF & $* * *$ & -0.0046 & $* *$ & -0.0041 & $* * *$ & -0.0080 & * & -0.0116 \\
\hline EXP & NS & + & NS & - & NS & - & $\mathrm{N} / \mathrm{A}$ & \\
\hline BANK & * & -0.0484 & NS & - & NS & - & NS & - \\
\hline GEN & NS & - & NS & - & NS & - & N/A & - \\
\hline MS & NS & - & NS & - & NS & - & N/A & - \\
\hline TEC & NS & + & N/A & + & NS & + & N/A & + \\
\hline TAXP & * & +0.1331 & NS & + & * & +0.1942 & NS & - \\
\hline SECM & NS & & N/A & & NS & & * & 0.3540 \\
\hline SECWR & $* * *$ & 0.0745 & $* * *$ & 0.0943 & NS & & NS & \\
\hline SECA & $* * *$ & 0.1360 & NS & & NS & & N/A & \\
\hline
\end{tabular}

${ }^{* * *} p<0.01,{ }^{* *} p<0.05,{ }^{*} p<0.1$.

workers who then neutralise the effects of poor education level on their part. The same cannot be said of micro enterprises with a maximum workforce size of 5 employees and an average workface size of 2 in the sample; a size too small to accommodate the key skills that may be lacking in the entrepreneur in positioning the business for growth.

Prior sector experience (PSE) which is usually jointly significant with education had a significant coefficient in the main model and in the case of SMEs category but insignificant under the individual category and the micro category. The insignificance under the individual sector category was driven largely by the dominance of agriculture and retailing businesses, which sectors do not require much prior experience before one can embark on them successfully. In the case of SMEs category, the coefficient of the variable PSE became significant in determining whether an enterprise grows or not. This sector was dominated by manufacturing industries where aspects to do with product quality and market access are heavily dependent on prior exposure in a related industry, determining one's workmanship and network for market penetration. Moreover, the SMEs sector was composed mainly of old enterprises that had matured enough ${ }^{11}$ Marginal effects included only for variables found to be significant at $1 \%, 5 \%$ and $10 \%$ levels in one of the size categories. 
to separate performance of those with experience from those without. Thus, those businesses run by entrepreneurs with prior sector experience stood a better chance of growing than their counterparts run by people without experience.

The coefficient of legal framework (LF) which was surprisingly insignificant in the main model only became significant in the case of SMEs carrying the expected positive sign implying that businesses that were formally constituted had a higher chance of growth than their unincorporated counterparts. Again, this is largely explained by the composition of the SMEs category with mature businesses whose survival is long enough to have separated the performance of those who were incorporated from those unincorporated and also reflecting the effects of the form of registrations on growth prospects. This result is the one more consistent with the ones in literature to the extent what Zimbabwe defines as SMEs fits perfectly well in the international definition of SMEs where most definitions exclude sole proprietors who apparently were in the majority (74\%) in the study sample, hence the seemingly contradictory results.

The banking variable (BANK) which had a significant coefficient at $10 \%$ level in the overall model was not significant in all the other sub-categories. This is probably because sole proprietors and micro enterprises don't usually use banks in Zimbabwe and where they do they use personal accounts as opposed to corporate business accounts. On the other hand, SMEs, by virtue of their being mature and therefore having survived, would suggest that the bulk of them would have opened corporate accounts by now and the effect of them not being banked would reflect the pattern and therefore relationship with growth. In all cases, the sign is surprisingly negative suggesting that those who were not banked had better chances of growth. This seemingly contradictory sign could be explained by the distortions in Zimbabwe's banking sector that has characterised the last two decades. The main reason for banking by small enterprises has been the need to access credit and this credit has not been easy to come by especially since the hyperinflationary era. The currency challenges and liquidity challenges compounded the distortions in the banking system, hence the negative relationship between banking and small firm growth. The sector in which a business is has a bearing on its growth prospects in all categories as it had on the overall model as evidenced by the significance of the coefficients of the different sector dummies being SECWR and SECA in micro category and SECM in the SME category.

In terms of marginal effects as depicted in Table 7 , the slopes of the significant variables ranged from $1 \%$ to $9 \%$, consistent with literature where most of these variables were found to have small individual effects on growth. In other words changes in the variable in question increased or decreased the probability of the small firm growing by between $1 \%$ and $9 \%$ for most variables under different categories.

The ones to have strong marginal effects in double digit include, MOT, PSE, and TAXP, SECj. In the case of the micro enterprises category, those who deliberately chose to be in business had a $10 \%$ more chance of growing their business 
than their counterparts who entered out of necessity. PSE had a marginal effect of $25 \%$ whilst TAXP had a marginal effect of $19 \%$, suggesting that those who were tax compliant in the micro category were $19 \%$ more likely to grow than their counterparts who were not tax compliant. Thus, policies that enhance tax compliance are likely to have a significant impact on the growth of MSMEs. The sector in which an enterprise is in could explain as high as $35 \%$ variation in the growth prospects of small firms in the SMEs category. Only AGE in the disaggregated models remained consistently insignificant just like under the main model suggesting that it definitely has no significant relationship with growth of MSMEs in Zimbabwe whichever way defined. This could be explained by the disproportionate weight of MSMEs in the start-up phase.

\section{Conclusion and Policy Implications}

The paper presented results of the determinants of MSMEs by sub-category in terms of the definition of MSMEs as amended in 2011. The variables that proved robust include, AGEF and MOT whose coefficients were found to be significant in at least two of the three sub-categories in addition to being significant in the main model. The ED, LF, TAXP, BANK, PSE and sector variables produced mixed results with coefficients being significant in at least one of the three subcategories to reflect peculiarities in the respective categories, whose peculiarities had been lost in the main model. AGE, MS, GEN, EXP and TEC remained consistently insignificant across the models.

The implications for policy are that the demographics of the MSMEs need to be taken into consideration in coming up with policy interventions to grow the sector. It is especially so, given the extension of the definition from SMEs to MSMEs, otherwise the anatomy of the Zimbabwean SMEs sector would create distortions if the narrow definition had been kept, yet broadening it creates its own challenges unless the heterogonous nature is acknowledged.

Modelling MSMEs growth dynamics by MSMEs sub-category revealed that legal framework variable which had been deemed insignificant in earlier formulations proved strongly significant in the SME category. This implies that the MSMEs formalisation crusade should target firms in the SMEs category first where formally registered SMEs have a higher chance of growth than those operating informally. Thus, formalisation efforts targeted at this group are likely to yield better results than trying to capture the millions of MSMEs in a blanket way. Equally so, targeting the micro category to graduate them into the SME category will help deal with the challenge of the missing middle which tends to constrain the contributions of the MSMEs sector to the economy.

The significance of the educational background and prior sector experience of the entrepreneur point towards the need to innovatively attend to the capacity constraints of small firm owners/managers. Whilst traditional approaches have focused on training the entrepreneur as a precondition for accessing loans, the results have not been encouraging. There is scope to come up with a model that 
recognises the need to capacity-build the entrepreneur whilst acknowledging the limitations in the ability of the entrepreneur to assimilate new information and acquire new skills. This will help overcome growth constraints associated with small firms.

Interventions to grow the MSMEs sector should focus more on young firms than those that have stagnated over the years with little chances of growth. This, has significant implications to the current government thrust of trying to revive old failed firms. Simultaneously, interventions should be focused more on the small to medium enterprises as they have a higher chance of growth in response to the policy stimulus than their micro counterparts. Policies targeted at one-man shops should be minimised with resources targeted at partially established firms as opposed to those in the start-up phase constituted mainly by sole proprietors. The universal failure rate of $95 \%$ for start-ups should, thus, guide policymakers in terms of targets for policy interventions in the MSMEs sector. Thus, efforts to grow the MSMEs should be targeted at those MSMEs that would have survived. This is particularly significant given that most entrepreneurs' motives for being in enterprise were more to do with survival than a deliberate choice to be in business, hence failure to endure corporate birth pains.

Survey data has the shortcoming that it gives the status of the studied phenomena at a point in time. A follow up study using time series data for the post Zimdollar era and post hyperinflationary era (the period 2009-2018) could produce different results. The study could also have suffered from the survivorship bias as the sample studied is only those who had survived by the time of the survey and therefore could not establish the growth dynamics of MSMEs which had failed. Incorporating in the sample MSMEs beyond the ones that survived could only be possible if it was time series data tracking the performance of the MSMEs over time. Future studies using alternative proxies for size like turnover and balance sheet size could also help validate the robustness of these findings.

\section{Acknowledgements}

Great appreciation goes to FinMark Trust for granting Moses Chundu authority to use the FinScope Zimbabwe 2012 Small Business survey data for academic research purposes in his $\mathrm{PhD}$ studies out of which this paper is derived.

\section{Conflicts of Interest}

The authors declare no conflicts of interest regarding the publication of this paper.

\section{References}

Almus, M., \& Nerlinger, E. A. (2000). Testing “Gibrat's Law” for Young Firms-Empirical Results for West Germany. Small Business Economics, 15, 1-12.

https://doi.org/10.1023/A:1026512005921

Audretsch, D., \& Klepper, S. (2000). Innovation, Evolution of Industry and Economic 
Growth.

Becchetti, L., \& Trovato, G. (2002). The Determinants of Growth for Small and Meduim Sized Firms. The Role of the Availability of External Finance. Small Business Economics, 19, 291-306. https://doi.org/10.1023/A:1019678429111

Blackburn, R. A., Hart, M., \& Wainwright, T. (2013). Small Business Performance: Business, Strategy and Owner-Manager Characteristics. Journal of Small Business and Enterprise Development, 20, 8-27. https://doi.org/10.1108/14626001311298394 http://www.emeraldinsight.com/doi/10.1108/14626001311298394

Chipangura, A., \& Kaseke, N. (2012). Growth Constraints of Small and Medium Enterprises (SMEs) at Glenview Furniture Complex (GFC) in Harare (Zimbabwe). International Journal of Marketing, 2, 39-83.

Churchill, N. C., \& Lewis, V. L. (1983). The Five Stages of Small Business Growth. https://papers.ssrn.com/sol3/papers.cfm?abstract_id=1504517

Cottrell, A., \& Lucchetti, R. J. (2016). Gretl User's Guide: Gnu Regression, Econometrics and Time-Series Library.

Cramer, J. S. (2005). Omitted Variables and Mis-Specified Disturbances in the Logit Model. Tinbergen Institute Discussion Paper.

Davidsson, P., Achtenhagen, L., \& Naldi, L. (2005). Research on Small Firm Growth: A Review (pp. 1-59). European Institute of Small Business.

Davidsson, P., Kirchhoff, B., Hatemi-J, A., \& Gustavsson, H. (2002). Empirical Analysis of Growth Factors Using Swedish. Journal of Small Business Management, 40, 332-349. https://doi.org/10.1111/1540-627X.00061

Delmar, F., \& Davidsson, P. (1998). A Taxonomy of High-Growth Firms. In Babson College-Kauffman Entrepreneurship Research Conference, Massachusetts, 1-13. https://fusionmx.babson.edu/entrep/fer/papers98/XIV/XIV_A/XIV_A.html

Dobbs, M., \& Hamilton, R. T. (2007). Small Business Growth: Recent Evidence and New Directions. International Journal of Entrepreneurial Behaviour and Research, 13, 296-322. https://doi.org/10.1108/13552550710780885

Doern, R. (2009). Investigating Barriers to SME Growth and Development in Transition Environments. International Small Business Journal: Researching Entrepreneurship, 27, 275-305. https://doi.org/10.1177/0266242609102275

Fatoki, O. O. (2011). The Impact of Human, Social and Financial Capital on the Performance of Small and Medium-Sized Enterprises (SMEs) in South Africa. Journal of Social Sciences, 29, 193-204. https://doi.org/10.1080/09718923.2011.11892970

Federico, J., Rabetino, R., \& Kantis, H. (2012). Comparing Young SMEs' Growth Determinants across Regions. Journal of Small Business and Enterprise Development, 19, 575-588. https://doi.org/10.1108/14626001211277406

Florin, J., Lubatkin, M., \& Schulze, W. (2003). A Social Capital Model of High-Growth Ventures. The Academy of Management Journal, 46, 374-384.

https://www.jstor.org/stable/30040630 https://doi.org/10.2307/30040630

Garnsey, E., Stam, E., \& Hefferman, P. (2006). New Firm Growth: Exploring Processes and Paths. Industry and Innovation, 13, 1-20. https://doi.org/10.1080/13662710500513367

Gielnik, M. M., Zacher, H., \& Schmitt, A. (2017). How Small Business Managers' Age and Focus on Opportunities Affect Business Growth: A Mediated Moderation Growth 
Model. Journal of Small Business Management, 55, 460-483.

https://doi.org/10.1111/jsbm.12253

Greene, W. H. (2002). Econometric Analysis (5th ed.). Upper Saddle River, NJ: Prentice Hall.

Hamilton, R. T., \& Lawrence, L. (2001). Explaining Size Differences in Smaller Firms. International Small Business Journal: Researching Entrepreneurship, 19, 49-60.

https://doi.org/10.1177/0266242601192003

Havnes, P., \& Senneseth, K. (2001). A Panel Study of Firm Growth among SMEs in Networks. Small Business Economics, 16, 293-302.

https://doi.org/10.1023/A:1011100510643

IFC (2010). Scaling-Up SME Access to Financial Services in the Developing World. In G20 Seoul Summit (pp. 1-144). Washington DC: Publisher World Bank Group.

Kangasharju, A. (1999). Growth of the Smallest: Determinants of Small Firm Growth. Pellervo Economic Research Institute Working Papers 21.

Karedza, G., Nyamazana, M. S., Mpofu, T., \& Makurumidze, S. (2014). An Analysis of the Obstacles to the Success of SMEs in Chinhoyi. European Journal of Business and Management, 6, 38-42. http://www.iiste.org

Mambula, C. (2002). Perceptions of SME Growth Constraints in Nigeria: University of Liverpool Library. Journal of Small Business Management, 40, 58-65.

http://eds.b.ebscohost.com.liverpool.idm.oclc.org/eds

https://doi.org/10.1111/1540-627X.00039

Mbugua, J. K. et al. (2013). Factors Affecting the Growth of Micro and Small Enterprises: A Case of Tailoring and Dressmaking Enterprises in Eldoret. International Journal of Business and Social Science, 4, 285-293.

https://pdfs.semanticscholar.org/98ec/952e042396c6d1126f953e713d56ca7f7bc6.pdf

McMahon, R. G. P. (1998). 98-5 Research Paper Series Stage Models of SME Growth Reconsidered. Adelaide South.

Mudavanhu, V., Bindu, S., Chigusiwa, L., \& Muchabaiwa, L. (2011). Determinants of Small and Medium Enterprises Failure in Zimbabwe: A Case Study of Bindura. International Journal of Economy Research, 2, 82-89.

Nichter, S., \& Goldmark, L. (2009). Small Firm Growth in Developing Countries. World Development, 37, 1453-1464. https://doi.org/10.1016/j.worlddev.2009.01.013

OECD (2017). Enhancing the Contributions of SMES in a Global and Digitalised Economy. In Meeting of the OECD Council at Ministerial Level (pp. 1-24). Paris: OECD Publishing. https://www.oecd.org/mcm/documents/C-MIN-2017-8-EN.pdf

Okpara, J. O. (2011). Factors Constraining the Growth and Survival of SMEs in Nigeria: Implications for Poverty Alleviation. Management Research Review, 34, 156-171. https://doi.org/10.1108/01409171111102786

Olson, P. D., \& Bokor, D. W. (1995). Strategy Process-Content Interaction: Effects on Growth Perf. Journal of Small Business Management, 33, 34.

Orser, B. J., Hogarth-Scott, S., \& Riding, A. L. (2000). Performance, Firm Size, and Management Problem-Solving. Journal of Small Business Management, 38, 42-58. https://www.researchgate.net/profile/Barbara_Orser/publication/274698692

Penrose, E. T. (1959). The Theory of the Growth of the Firm. New York: Oxford University Press.

Reichstein, T., \& Dahl, M. S. (2004). Are Firm Growth Rates Random? Analysing Patterns 
and Dependencies. International Review of Applied Economics, 18, 225-246. https://doi.org/10.1080/0269217042000186705

Rogerson, C. M. (2001). In Search of the African Miracle: Debates on Successful Small Enterprise Development in Africa. Habitat International, 25, 115-142.

http://linkinghub.elsevier.com/retrieve/pii/S0197397500000333 https://doi.org/10.1016/S0197-3975(00)00033-3

Sachikonye, S., \& Sibanda, M. (2016). An Assessment of Financing of SMEs in Zimbabwe by Commercial Banks. Acta Universitatis Danubius. Economica, 12, 213-224. http://journals.univ-danubius.ro/index.php/oeconomica/article/viewFile/3445/3733

Shin, J., \& Park, S. (2013). Growth Determinants of SMEs in the Korea Nuclear Equipment Market. Academy of Entrepreneurship Journal, 19, 175.

http://search.ebscohost.com/login.aspx?direct=true\&db=bth\&AN=96115080\&site=eho st-live

Sirec, K., \& Mocnik, D. (2010). How Entrepreneurs' Personal Characteristics Affect SMES' Growth. Izvirni Znanstveni Članki.

Sleuwaegen, L., \& Goedhuys, M. (2002). Growth of Firms in Developing Countries, Te d'Ivoire Evidence from Co. Journal of Development Economics, 68, 117-135. http://www.sciencedirect.com/science/article/pii/S0304387802000081 https://doi.org/10.1016/S0304-3878(02)00008-1

Snodgrass, D. R., \& Biggs, T. (1996). Industrialization and the Small Firm: Patterns and Policies.

Storey, D. J. (1994). Understanding the Small Business Sector. New York: Routledge. https://www.taylorfrancis.com/books/9781315544335

Strassburg, S., \& Khumalo, J. (2012). Zimbabwe-FinScope MSME Survey 2012. Johannesburg, South Africa.

http://documents.worldbank.org/curated/en/780081468137402417/Zimbabwe-FinScop e-MSME-survey-2012

Tuan, N., \& Yoshi, T. (2009). Factors Contributing to the Growth of Small and Medium Enterprises: An Empirical Analysis of Vietnam's Manufacturing Firms. Singapore Management Review, 31, 35-52.

Wijewardena, H., \& Tibbits, G. E. (1999). Factors Contributing to the Growth of Small Manufacturing Firms: Data from Australia. Journal of Small Business Management, 37, 88-96.

Wiklund, J. (1998). Small Firm Growth and Performance Entrepreneurship and Beyond (pp. 1-361). Doctoral Thesis, Jönköping: Jönköping International Business School.

Woldie, A., Leighton, P., \& Adesua, A. (2008). Factors Influencing Small and Medium Enterprises (SMEs): An Exploratory Study of Owner/Manager and Firm Characteristics. Banks and Bank Systems, 3, 5-13. https://repository.cardiffmet.ac.uk/handle/10369/2701

Yasuda, T. (2005). Firm Growth, Size, Age and Behavior in Japanese Manufacturing. Small Business Economics, 24, 1-15. https://doi.org/10.1007/s11187-005-7568-y

Yeboah, M. A. (2015). Determinants of SME Growth: An Empirical Perspective of SMES in the Cape Coast Metropolis, Ghana. The Journal of Business in Developing Nations, 14, 1-31.

Zindiye, S. (2008). An Empirical Investigation into the Factors Affecting the Performance of Small and Medium Enterprises in the Manufacturing Sector of Harare, Zimbabwe. Alice: Univeristy of Fort Hare. 
M. Chundu et al.

ZNCC (2017). Survey on Understanding the Dynamics and Characteristics of the Informal Sector in Zimbabwe. Harare. 